\title{
Review of University Teaching in Focus: A Learning- Centred Approach
}

From process to product, this text provides an impressive account of teaching, learning, scholarship and leadership. The contributors have a wealth of experience and actively research the complex issues identified within the text.

The content sews together a rich fabric of essential elements for both new teachers and experienced lecturers in the higher education sector. Divided thematically into different chapters, University Teaching in Focus: A Learning-Centred Approach charts an interesting journey across learner, curriculum, teaching and leadership and management. Punctuated with examples and practical guidelines, the editors have done well to succinctly position practice in theory. Each chapter, within itself, provides a platform for reflection, improvement and transformation of teaching practice and philosophy. Critical analyses are carefully woven into the scholarship of teaching and learning through the identification of important questions and evaluative statements that further trigger enquiry into different aspects of higher education teaching.

Chapter authors bring a truly international perspective by considering universal collectives and sharing experiences across borders and territories. Whilst there are numerous texts that challenge and explain pedagogies, assessment frameworks and teaching methodologies, few are able to integrate international perspectives on these topics. This text not only integrates multiple and often complex views on higher education teaching, but further illustrates problems, barriers, opportunities and dilemmas associated with entry level teaching.

Teaching in higher education is a complex practice that demands consideration of different theoretical perspectives, philosophies, and methodologies. Through smart editing, the editors allow the reader to digest snippets of practical teaching and then work towards resolution of problematic issues. Each chapter is flooded with diverse and current resources and references. This provides a springboard for early career academics by allowing them to read and digest the signature scholars' research in teaching and learning, many of whom have actively contributed to the text. This is useful as it encourages reflection on a range of theory and practice.

One area that could be strengthened is that of teaching and learning fellows and mentors. Although some chapters speak to teaching excellence, it would be interesting to consider the role and support that institutional and national fellows bring to the advancement of teaching practice and support of the work of entry-level academics. One potential inclusion could be a discussion of academic identity as it is affected by the differing cultures of discipline-specific enquiry and the broader landscape of the Scholarship 
of Teaching and Learning (SoTL). A powerful analysis of whether entry-level academics forge an identity of SoTL scholarship or become SoTL practitioners enriched within a discipline specific domain would add value to the content for the text.

Overall the book is highly effective as each topic component has been carefully introduced, analysed, debated, and practically presented in a clear and concise manner. The examples used to illustrate core theories and ideas are well managed and provide an interesting profile for future academic and professional development. The strength of the text lies not only in the rich contribution it makes to academic advancement, but more so in answering the question about what teaching in higher education means and how best to engage curriculum, learning, teaching and management in a productive and progressive debate.

The authors help us understand how we tend to think about teaching and learning, and how we teach our students to think. Readers of this book will be able to take teaching and learning processes into account when making decisions related to curriculum design and management. The book promotes thoughtful analysis and encourages the reader to actively engage in current issues of teaching and learning.

A must have text for all academics and scholars that carefully considers theories and plans for practice in a reflective and thought-provoking way.

Earle Abrahamson co-chairs the ISSOTL multinational teaching fellows group, is a legal and governance consultant with the Vice Chancellor group at the University of East London, and researches academic identity and troublesome knowledge. 